\title{
Reforma psiquiátrica, trabalhadores de saúde mental e a "parceria" da família: o discurso do distanciamento"
}

Leandro Barbosa de Pinho ${ }^{1}$

Antonio Miguel Bañon Hernández²

Luciane Prado Kantorski ${ }^{3}$

PINHO, L.B.; HERNÁNDEZ, A.M.B.; KANTORSKI, L.P. Psychiatric reform, mental health workers and the family's "partnership": the discourse of distancing. Interface - Comunic., Saude, Educ., v.14, n.32, p.103-13, jan./mar. 2010.

This study analyzed the discourse of mental health workers regarding family participation in treatment. The corpus consisted of interviews applied to 17 of the 25 professionals working in a substitutive service in a city in southern Brazil. The theoretical-philosophical framework was critical discourse analysis. The methodological device that supported the systematization of the data was the "axiological-discursive diagram". It was found that the workers expressed the importance of the family in treating user, but with representation still based on assigning responsibility and blame when the family moves away from the treatment. Gradually, the "partnership" gives way to "distancing" as a care dimension within the mental health services. It is hoped that this study will support continuing reflection on the role of families in mental health, which is an important issue in rethinking knowledge and practices relating to lunatics and madness, and their relationship within the context of psychiatric reform.

Keywords: Language studies. Mental health. Mental health services.
Este estudo analisou o discurso de trabalhadores de saúde mental sobre a participação da família no tratamento. O corpus foi composto por entrevistas aplicadas a 17 dos 25 profissionais que trabalham em um serviço substitutivo de uma cidade da região Sul do Brasil. O referencial teórico-filosófico foi a Análise Crítica do Discurso. O dispositivo metodológico que subsidiou a sistematização dos dados foi o "diagrama axiológico-discursivo". Verificou-se que os trabalhadores manifestam a importância da família no tratamento do usuário, entretanto, representação ainda pautada na responsabilização e culpabilização, quando a família se afasta do tratamento. Aos poucos, a "parceria" vai dando espaço ao "distanciamento", como dimensão cuidadora nos serviços de saúde mental. Espera-se que este estudo subsidie a constante reflexão sobre o papel das famílias em saúde mental, temática importante para repensar saberes e práticas sobre o louco, a loucura e suas relações no contexto da reforma psiquiátrica.

Palavras-chave: Estudos de linguagem. Saúde mental. Serviços de saúde mental.

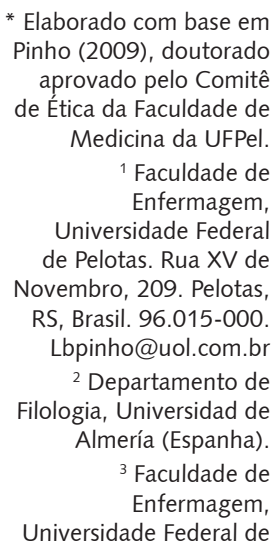

* Elaborado com base em Pinho (2009), doutorado aprovado pelo Comitê de Ética da Faculdade de Medicina da UFPel.

${ }^{1}$ Faculdade de Enfermagem Universidade Federal de Pelotas. Rua XV de Novembro, 209. Pelotas, RS, Brasil. 96.015-000.

Lbpinho@uol.com.br 2 Departamento de Filologia, Universidad de Almería (Espanha).

${ }^{3}$ Faculdade de Enfermagem, Universidade Federal de Pelotas. 


\section{Introdução}

A reforma psiquiátrica compreende um movimento jurídico, político, social e cultural, que busca reorientar determinados saberes e fazeres conflituosos, ao longo de anos, sobre o fenômeno da loucura. Mais especificamente, procura superar um modelo que ganhou força com o advento da medicina científica na era moderna, quando a loucura é elevada à categoria de doença mental e deveria, por isso, ser afastada com o subterfúgio do discurso de tratamento e internada em instituições especializadas (Luz, 2008).

No modelo asilar, de herança pineliana, o louco era considerado um indivíduo perigoso, desarrazoado pela sua própria condição de doente, o qual deveria ser contido em espaços hospitalares psiquiátricos para livrar-se dos vícios de sua razão delirante. Nesse sentido, o modelo asilar preconizava o afastamento do doente de seus vínculos, já que a reaprendizagem social viria pela dedicação integral e submissão às regras e rotinas da instituição manicomial (Costa-Rosa, 2000).

Nesse sentido, testemunhou-se uma ênfase generalizada na família como aquela cúmplice resignada e grata pela internação do paciente. Isso porque a família não era vista como parceira, mas como um sistema doente, fragilizado, sendo parcialmente culpabilizada pela doença de seu parente. Em prol da recuperação, o doente deveria ser afastado do convívio com a família, pois somente assim era possível resgatar o indivíduo e restabelecer sua razão desviada pelos vícios oriundos da situação de doença mental (Saraceno, 2001).

Se no contexto manicomial a família é deslocada para fora do tratamento, no contexto da reforma psiquiátrica ela passa a ser entendida como o cenário fundamental da recuperação do sujeito em sofrimento mental. Isso porque a família é a conexão desse indivíduo com a sua comunidade e, mesmo que também esteja doente, ela deve ser incluída, acolhida, tratada e cuidada no interior dos serviços, como protagonista do tratamento (Lobosque, 2007).

Assim, a família é retomada não como cúmplice, mas como parceira; não como agente etiológico, mas como uma rede de relações, um suporte para o indivíduo enfrentar condições de adversidade em sua vida. A família é uma extensão dos laços afetivos, possui seu próprio sistema de crenças, costumes, experiências e vínculos sociais, assim como um modo peculiar de organização na sociedade. Portanto, a família vai além do elo de parentesco para ser elevada à condição de aliada na luta contra o sofrimento imposto pelo transtorno mental.

No entanto, entendemos que inserir o círculo de relações do louco durante o tratamento vai além das expectativas depositadas pela própria potência do movimento no contexto brasileiro. Já há alguns estudos (Oliveira, Alessi, 2005; Arejano, 2002) que discutem a interlocução de determinados saberes e fazeres "antirreformistas" em pleno seio de transformações, quando os trabalhadores deslocam objetos de trabalho centrado no sujeito para desenvolver instrumentos voltados para o tratamento da doença. Também é possível analisar certas práticas direcionadas para o estabelecimento de relações de tutela e culpabilização das famílias, como resquícios de uma atenção normalizadora e concentrada no poder disciplinar.

Nesse sentido, a tarefa de inserir os vínculos afetivos dos usuários no tratamento parece esbarrar em determinados vieses manicomiais, os quais reproduzem discursos em que a retórica da verdade passa a ser o saber que pouco liberta e muito exclui. Isso também é responsável por perpetuar estereótipos sociais que enxergam a loucura como um potencial limitante da vida e um perigo social, um problema que a família não está preparada para resolver e deve se afastar para permitir o tratamento.

Este estudo, portanto, pretende analisar o discurso de trabalhadores de saúde mental de um serviço substitutivo sobre a participação da família no tratamento. Procurou-se identificar contradições, manifestações e conflitos presentes nos discursos, de modo evidenciar os movimentos de aproximação e distanciamento que se deslocam dialeticamente no espaço social de cuidados. 


\section{Metodologia}

Trata-se de uma pesquisa de abordagem qualitativa. O corpus deste trabalho é composto por entrevistas aplicadas a 17 dos 25 profissionais de saúde mental que trabalham em um serviço substitutivo de uma cidade da Região Sul do Brasil e que se dispuseram a participar da pesquisa. Foram aplicadas três perguntas-chave, a saber: 1 Fale sobre o atendimento no serviço; 2 Fale sobre os fatores que podem contribuir para um melhor funcionamento do serviço, e 3 Fale sobre sua prática em saúde mental nesse CAPS. As entrevistas foram gravadas em fitas cassete e, depois de concluídas, encaminhadas a dois digitadores diferentes, responsáveis pela transliteração das gravações.

Nos estudos do discurso, a transcrição concentra-se na descrição detalhada de todos os fenômenos semióticos envolvidos nas conversações, como: pausas, entonações, corte de sílabas ou sinais verbais/ não verbais. No caso da transliteração, compreende-se a transcrição dos signos linguísticos, mas utilizando-se uma ortografia convencional para descrever apenas os enunciados produzidos pelos falantes, sendo o nível mais comum de representação de todos os corpus orais (Llisteri, 2008).

O referencial teórico-metodológico que orientou a análise foi a Análise Crítica de Discurso (Fairclough, 2006). Os dados foram organizados conforme o dispositivo chamado de "Diagrama Axiológico-Discursivo" (Pinho, 2009). Essa metodologia foi desenvolvida no intuito de encontrar certo padrão discursivo nos informantes, ou seja, um "discurso prototípico", que, por ser naturalmente valorativo, já que agrega juízos de valor a comportamentos ou ações humanas, está inserido no âmbito da axiologia. No caso das famílias, a aplicação do dispositivo revelou que o discurso dos trabalhadores sobre elas está voltado para o "distanciamento". E também mostrou o padrão ideológico do trabalhador sobre a família, vista como um sistema que deposita suas responsabilidades no serviço e se afasta, quando deveria estar participando ativamente do tratamento.

Como o objetivo era poder encontrar um padrão discursivo que revelasse a intenção de todos os informantes, não é necessário reproduzir fragmentos discursivos de todos eles. Optamos por apresentar apenas o discurso mais representativo da dimensão axiológica analisada e alguns fragmentos do mesmo, que possam contemplar a representação do distanciamento.

O projeto foi submetido previamente a avaliação pelo Comitê de Ética em Pesquisa da Faculdade de Medicina da Universidade Federal e Pelotas (UFPel), obtendo parecer favorável ao seu desenvolvimento. Foi, também, garantido o anonimato dos sujeitos do estudo e respeitados todos os preceitos ético-legais que regem a pesquisa com seres humanos, como é preconizado pelo Ministério da Saúde (Resolução 196/96 do Conselho Nacional de Saúde) e Código de Ética dos Profissionais de Enfermagem.

\section{Resultados e discussões}

Qualquer situação de adoecimento ou sofrimento pode alterar a nossa percepção do mundo. A doença é um processo que faz parte do contexto da vida, sendo, por isso, impossível dissociá-la como uma entidade independente. A doença às vezes limita, é ansiogênica, prejudica o desenvolvimento das atividades cotidianas e, também, traz influências na constituição das relações entre os sujeitos. A doença altera nossa maneira de viver coletivamente, a nossa relação com o mundo e, mais intimamente, a nossa família.

Uma situação de enfermidade crônica gera um impacto psicossocial importante na família. No entanto, toda a situação eminentemente progressiva pode ajudar na consolidação dos vínculos emocionais entre os familiares, pois dá à família mais tempo para preparar-se para as mudanças antecipadas. Em especial, vai proporcionando a todos um reajustamento temporal, além de uma aprendizagem significativa sobre o problema clínico, a administração dos momentos de crise e a alternância de papéis (Rolland, 2001).

Nesse sentido, entendemos que qualquer situação de adversidade pode ajudar na descoberta de novos potenciais e novos vínculos afetivos dentro do grupo familial. Isso quer dizer que o agente estressor até pode provocar alterações no modo de vida da família, mas também ajuda no processo 
de readaptação ao momento, fortalecendo os laços de amizade, o respeito, a solidariedade e a convivência pacífica entre os membros do grupo.

A família é a célula-mestra da sociedade contemporânea, atuando não somente na constituição existencial dos indivíduos, como também na proteção e socialização de seus membros (Romagnoli, 2006). Em situações potencialmente estressoras, como no processo de adoecimento, todo o contexto familial é afetado. Isso porque a família é uma continuidade da vida do sujeito, ela possui suas crenças, seus costumes, inclusive pode sofrer, juntamente com seu parente, as experiências limitantes causadas pela doença. O serviço de saúde que consegue adaptar-se ao modo de operar centrado no sujeito e passa a incluir a família como parceira em seus cuidados ajuda no fortalecimento de vínculos, na maior integração entre os indivíduos e no desenvolvimento integral do ser humano (Pulido, Monari, Rossi, 2008).

Em se tratando de serviços substitutivos, um dos objetivos é incentivar a família a participar da melhor forma possível e viável do cotidiano assistencial dos serviços. Os familiares, muitas vezes, são o elo mais próximo que os usuários têm com o mundo, sendo, por isso, um sistema muito importante para o trabalho dos CAPS. A inclusão da família como copartícipe do tratamento vai além do mero incentivo ao usuário, mas sobretudo pela participação direta nas atividades do serviço, tanto internas como externas (Brasil, 2004).

Os trabalhadores têm consciência da importância da família no tratamento do usuário. Fato este traduzido no desenvolvimento de atividades voltadas para ela. $\mathrm{O}$ fragmento abaixo discute um pouco a proposta inclusiva do serviço em relação ao familiar:

\footnotetext{
Investigador - " $[\ldots .$.$] Inicialmente eu queria que tu comentasses sobre o atendimento no serviço.$ É claro que a gente já vem comentando informalmente, mas eu gostaria que tu pudesses comentar alguma coisa pra ficar registrado".

Trabalhador - "Bom o atendimento é... pra pessoas com transtornos mentais graves, né? A gente atende é... os usuários acima de 16 anos, é um trabalho direcionado pro usuário, pro usuário que ta apresentando esse transtorno mental né, grave, ta na sua fase evolutiva, a gente retoma, então a gente prioriza os que são mais graves, vamos dizer assim, né, que tão com sintomas mais exacerbados e existe também o atendimento voltado pro familiar, né? Que ele seria um, uma retaguarda também pro familiar no atendimento, desse, além de estar, é, recebendo também um atendimento, mas a gente vê que esse, ah, 50\% vamos dizer assim, do atendimento, da eficácia vai depender também da participação desse familiar, né, pra ele ta inserido nesse tratamento né, colaborando também com esse tratamento né? É... o atendimento diário, das 7 as $18 \mathrm{hs}$, é... a gente ta cadastrado como CAPS II, por causa até da questão do município ter uma população acima de 200.000, a gente ta com 480.000 habitantes, né...é...eu vejo que um atendimento na área de saúde mental diferenciado, né, nós temos um atendimento de, pra transtornos mentais na rede básica de saúde e esse atendimento que está hoje no, é considerado da rede básica, é uma referência, é dentro do serviço de referência. Acho que é isso".
}

No contexto de transformações da assistência psiquiátrica, uma instituição que se propõe a inserir a família dentro do plantel de práticas está responsabilizando-se por ela como se fosse uma extensão das relações sociais dos usuários. Em outras palavras, quando atendemos o usuário, devemos pensar que, por trás dele, existe um sistema que pode ou não estar vivenciando uma situação de sofrimento. Atendê-lo, acolhê-lo e incluí-lo pode, nesse sentido, ser o primeiro passo em direção ao redimensionamento do cuidado psiquiátrico no interior dos serviços.

Existe uma expressão gramatical que possibilita pensar em quanto o serviço está preocupado em atender as demandas da família. Nessa construção, o recurso linguístico utilizado se trata de um conector aditivo (" $\mathrm{e}$ "). Logo após o sujeito discorrer sobre o atendimento com base no perfil da clientela (já discutido anteriormente), o trabalhador se utiliza desse conector para mostrar que também existe atendimento ao grupo familial, como um evento paralelo e complementar ao do indivíduo em sofrimento mental. 
O fato de os trabalhadores lembrarem-se da família dentro das práticas do serviço já revela uma ampliação teórica e técnica da dimensão do cuidado em saúde mental, compatível com as prerrogativas de um modelo de atendimento que luta pela inclusão de um sistema naturalmente excluído do contexto de tratamento. Entretanto, no momento em que o trabalhador afirma que "também existe atendimento ao familiar", ele chama a atenção para a própria concepção institucional de família assumida pelo serviço, que parece incerta. Ao dizer que também existe atendimento ao familiar, ele tanto pode estar pensando na família como um coletivo singular para o qual o serviço está atento, como também pode não ter a percepção suficiente de que a família é um sistema que faz parte do contexto de vida do usuário.

Nesse contexto, há uma palavra que, de certa maneira, ajuda no esclarecimento dessas incertezas. A família parece ser lembrada no discurso do trabalhador como alguém que precisa de "retaguarda". Do ponto de vista discursivo, essa é uma das primeiras representações dos trabalhadores em relação ao atendimento ao grupo familial. A palavra "retaguarda" aqui está deslocada de seu contexto original (o contexto militar), no entanto, parece ter seu sentido preservado. Nesse caso, ela participa do rol de linguagens trópicas, sendo aqui utilizada como metáfora.

A metáfora faz parte do uso figurativo da linguagem, como parte do rol de conhecimentos retóricos que buscam modificar a forma de recepção da mensagem ao interlocutor. A essência da metáfora está relacionada à possibilidade de se conhecerem e experimentarem determinados conceitos no lugar de outros, uma vez que a metáfora apenas sobrevive se existirem pessoas dentro do sistema conceitual. É dizer que uma metáfora pode servir de veículo para a compreensão das coisas apenas pela força de sua base experiencial (Lakoff, 1980).

No contexto militar, quando oferecemos retaguarda a alguém, quer dizer que estamos fornecendo a esta pessoa proteção, segurança e confiança contra um momento de adversidade (uma guerra, por exemplo). No caso da saúde mental, a retaguarda à família significa que o serviço está atento às dificuldades da família e procura dar um suporte responsável, dinâmico e efetivo à desestabilização proporcionada pelo sofrimento mental. Quer dizer que, além do suporte e do apoio psicoemocional, os trabalhadores parecem estar preocupados com a inserção da família no tratamento, sobretudo quando esta (totalmente ou em parte) vivencia diariamente as circunstâncias limitantes do sofrimento, suas manifestações nem sempre espontâneas, bem como os cuidados, que exigem tempo e disponibilidade. Nesse caso, parece que os trabalhadores vêm buscando continuamente formas e estratégias para compartilhar, incluir e acolher suas demandas como parte do projeto terapêutico.

De outro lado, a questão do atendimento como uma "retaguarda" pode pressupor o desenvolvimento de diferentes reações entre os agentes do processo. Primeiro, podemos pensar numa consolidação de laços afetivos e de confiança emocional com a família, fundamentais num contexto em que se preconiza o vínculo contratual como instrumento genuíno de cuidado contemporâneo em saúde mental. Em segundo lugar, podemos perceber que a "retaguarda" pode enviesar esse mesmo cuidado e transformá-lo numa relação de dependência da família em relação ao serviço. Ou, em terceiro lugar, quando a "retaguarda" oferecida para a família passa a não ser correspondida, ou seja, quando a família resiste ao acompanhamento sistemático no serviço ou se afasta, sobretudo com o subterfúgio de aliviar as suas demandas psicoemocionais. Nesses dois últimos casos, pode ser que o vínculo entre profissionais e famílias esteja mediado por alguns conflitos na comunicação, cada um deles projetando, no outro, sucessos, desafios e impotências no decorrer do tratamento do usuário.

Em certo sentido, compreendemos que a participação da família é fundamental para a recuperação do indivíduo em sofrimento mental, justamente pelo fato de ela ser uma fonte de capitalização de forças que gera conforto, sensação de amparo e estabilidade. Contudo, uma família que vivencia uma situação de sofrimento mental também está sujeita a desenvolver uma série de sentimentos contraditórios em relação ao tratamento. Se, por um lado, o sofrimento já é um evento culturalmente estigmatizado, do qual a família tenta se proteger, por outro, ela busca um refúgio no serviço para que este lide com as questões mais complexas que envolvem o comportamento de seu parente. Nesse caso, é possível que a família delegue a responsabilidade do cuidado ao serviço como uma saída para o alívio da sobrecarga físico-emocional gerada pelo sofrimento mental. 
A família que vivencia uma situação de sofrimento mental está sujeita a passar por três tipos de sobrecarga. A primeira diz respeito à sobrecarga financeira, especialmente quando o indivíduo em sofrimento mental apresenta um conjunto de manifestações comportamentais que exigem atenção integral da família, comprometendo sua inserção no mercado de trabalho. Na segunda situação, ocorre a sobrecarga de cuidado, em que a família se situa entre a prestação de um cuidado zeloso e preocupado com o outro, mas que se desgasta pela necessidade contínua de readequação de suas atividades da vida cotidiana em função dos encargos gerados pelo sofrimento mental. Por último, temos a sobrecarga físico-emocional, com o aparecimento de problemas orgânicos ou psicológicos derivados do cuidado intensivo ao portador de sofrimento mental, como problemas gastrintestinais, privação do sono e esgotamento emocional (Borba, Schwartz, Kantorski, 2008).

Para a família de um parente com transtorno mental, o fardo que gera a sobrecarga é causado por uma série de determinantes físicos, emocionais e sociais. A família, geralmente, é responsável por prover toda a atenção e o acolhimento necessários ao parente doente. Isso cria uma demanda que extrapola as relações mais subjetivas, pois altera sua percepção sobre a conduta humana em sociedade, seus hábitos de vida diários (dormir, comer, entre outros), suas rotinas domésticas e externas, inclusive sua organização para enfrentar as dificuldades econômicas impostas pelo sofrimento, nem sempre de curto prazo. Com a readaptação das tarefas internas, algumas pessoas podem ficar mais sobrecarregadas que outras, e isso exige que a família busque constantemente estratégias de flexibilização, que demandam mais esforço e esgotamento por parte dela (Koga, Furegato, 2002).

No caso da saúde mental, todos os afetos (positivos ou negativos) sentidos pelos trabalhadores podem ser um sinal de como o relacionamento deles com as famílias ainda parece marcado mais pela responsabilização que pelo comprometimento genuíno. Por exemplo, no discurso anterior, é possível constatar a necessidade de participação da família durante o tratamento de seu parente, que, estando suficientemente envolvida na mesma medida que o serviço, potencializa o processo de intervenções no campo psicossocial. No entanto, se o sucesso do tratamento "vai depender" do envolvimento da família, é o mesmo que dizer que os trabalhadores se comprometem, mas que não parecem se responsabilizar por completo pelo tratamento. Assim, pode-se abrir uma lacuna entre o "dizer" do trabalhador - sobre o cuidado solidário, interessado pelo contexto da família - e o "fazer" - transportado para o terreno da responsabilização pelo não-envolvimento integral dela.

Assim, parece haver uma controvérsia no discurso dos trabalhadores com relação à inclusão da família, já que esta é lembrada como parceira do tratamento - o que a aproxima -, ao mesmo tempo em que há dificuldades de livrar-se de padrões discursivos, os quais impedem a superação dos modelos tradicionais de responsabilização e culpabilização do grupo familial - que distanciam. O discurso abaixo é um reflexo dessa realidade:

\footnotetext{
Investigador - "Então eu gostaria que tu me comentasse, né? Que tu me falasse sobre os fatores que possam contribuir para o melhor funcionamento do serviço".

Trabalhador - "Acho que uma coisa, uma capacitação geral de funcionários". Investigador - "[[Uhum::]]".

Trabalhador - " [[Um]] aumento assim, investir em capacitação, e nisso nossa secretaria de saúde é bem:: devagar... né? Eu acho que se poderia se investir mais na nossa capacitação... poderia melhorar os recursos, né? Verba, recurso financeiro, né? Poderia ser melhor pra gente poder fazer mais coisas, que nem, vai fazer uma festa junina e a gente acaba tendo de fazer::, tirar dinheiro do bolso pra comprar brinde pra poder fazer a festa.... então assim até o nosso carro que:: agora que a gente ta com essa ambulância ali, mas chegou uma época da gente andar com um carro sem fundo...que não tinha freio então você tem que andar com um carro que não tinha freio ...então assim, coisas bem precárias, então assim quando fala de saúde mental, eles mandam tudo que é resto que vai pra saúde mental (( rindo ))".

Investigador - "Uhum::. Então tu acha assim que a saúde mental nesse momento:::né? Hoje como ela esta sendo vista, ela fica meio que desacreditada [[no]] município, [[ é isso?]]".
} 
Trabalhador - "[[Aham]] [[bem]] eu acho que falta até que esteja um... aí lá a assembléia na câmara como é que é o nome? De lá partiu prum fórum, mas pensa num debate [[né]]?". Investigador - "[[Aham:]]".

Trabalhador - "E o que eu vi assim:: meu, tinha a Tânia que é vereadora, mas assim pouquíssimos vereadores, e ficaram o que, meia hora e foram embora, então um negócio assim, só foram pra consultar... tipo assim faltou interesse mesmo da nossa parte política, eu pensei assim que eles se interessassem mais... até mesmo a população, porque foi convidado os familiares, foi mandado convite pra quase tudo, e foi uma minoria de familiar, uma minoria de gente... então assim o povo não: se interessa muito".

Investigador - "Tu acha que a população também não se [[mobiliza]]?".

Trabalhador - "[[Não, não]]".

Investigador - "Normalmente a secretaria não se mobiliza:: pra ajudar a saúde mental e acreditar mais na saúde mental, a população [[também]]".

Trabalhador - "[[A população também]] não... mesmo porque a população assim ela:: falta orientar, se vê que é haver muito do cultural isso... mas é bem assim:, saúde mental é uma coisa marginalizada, né? Então assim paciente mental, ele não dá voto... E assim os que tão ali procurando é familiar que tem alguém com transtorno né? Que ta passando por essa dali é aquele que sim, né? Porque senão a maioria... e muitas vezes assim, o, por exemplo, o paciente mental, dificilmente ele tem família né? Que a família se afasta... [[e]]".

Inicialmente, ao discutir o (des) apoio da gestão municipal de saúde mental, o trabalhador comenta que falta interesse por parte dos familiares para participar das discussões. Essa relação de desinteresse foi explicada tendo por base o envio de convites que, no entanto, foram pouco correspondidos.

Para explicar as relações existentes entre a ausência da família e o desinteresse do ponto de vista do trabalhador, existem duas estruturas linguísticas a serem destacadas: uma delas diz respeito à hipérbole e a outra se refere ao uso de alguns marcadores discursivos.

A hipérbole é a modalidade figurativa da linguagem em que há novamente o emprego da subjetividade, desta vez de maneira exageradamente intencional (tanto pra cima como para baixo). Com as hipérboles, o foco desvia-se da palavra propriamente dita para acentuar, de forma relativamente "dramática", aquilo que se quer dizer, transmitindo uma imagem ampliada da realidade. O que determina o poder da hipérbole nas inscrições enunciativas não é o conteúdo informacional da sequência, mas a sua orientação argumentativa em relação ao contexto em que aparece (Charaudeau, Maingueneau, 2006).

A hipérbole inscreve uma funcionalidade na linguagem diferente de outras estruturas linguísticas. Por ser flexível a ponto de aumentar ou diminuir a expressividade de determinadas relações semânticas, a hipérbole sobrevive não por causa do exagero em si que provoca nos contextos conversacionais, mas por causa da compreensão exagerada que tem o interlocutor sobre esse contexto. No caso da saúde mental, no momento em que o trabalhador afirma que o serviço convidou os familiares dos usuários para participarem das reuniões, a contestação do convite veio na forma de uma "minoria de familiar", uma "minoria de gente". Como o diminutivo "minoria" aqui está funcionando como uma figura hiperbólica, ele dá a impressão de que o serviço fez um chamamento especial para praticamente toda a comunidade de Joinville ("quase tudo"), sendo, contudo, correspondido com uma pequena ou "quase insignificante" parte dela ("minoria de gente"). Assim, os trabalhadores se justificam, colocando-se numa posição resignada de que "fizeram o que podiam" e transferindo a responsabilidade pelos problemas internos durante o tratamento para a família. Entendemos que esse juízo negativo de valor é pouco compatível com a imagem positiva do compromisso e da preocupação anteriormente demonstrada.

Há um advérbio com seu adjetivo subsequente que está funcionando como marcador discursivo e que, também, permite realizar essa inferência ("dificilmente"). Na ocasião, o advérbio está intensificando uma atitude valorativa excludente (e equivocada) por parte do trabalhador, já que este parece referir-se ao usuário como se ele fosse um "ser sem vínculos". Isso quer dizer que o indivíduo, quando se transforma em usuário do serviço, ficaria sem família, já que o serviço 
convoca, oferece atendimento e ela não comparece. Fica aqui um jogo truncado de "transferência de responsabilidades", como se a família responsabilizasse o serviço pelo cuidado, por ser sua obrigação, e o serviço responsabilizasse a família pelo afastamento do tratamento.

Claro que o trabalhador procura argumentos convincentes para o fato do distanciamento da família no tratamento. Seu discurso se volta para o estabelecimento de certas relações de implicação, todas elas transferindo graus de responsabilidades para o grupo familial (valorações negativas do ponto de vista de juízos de valor).

Por exemplo, ao ser convidada e não comparecer, isso dá margem para o trabalhador imaginar que a família está afastada. Agora, se ela está afastada porque transfere o cuidado para os trabalhadores, é porque ela está desinteressada pelo tratamento. E se ela está desinteressada é porque desconhece o fenômeno da loucura e a sua própria importância como copartícipe do tratamento. O interessante nessa implicação é que existe uma intenção de transferir responsabilidades para a família, quando, na verdade, forma-se um circuito que se inicia e termina na equipe, pois ela responsabiliza a família (pelo afastamento), mas fica responsabilizada implicitamente (pelo desconhecimento da família).

A expressão atenuante "não se interessa muito" complementa essas implicações. Na verdade, quando dizemos que alguém "não se interessa muito", isto assemelha-se a dizer que essa pessoa "se interessa quase nada". O trabalhador não quer ser ameaçador no contexto conversacional, o que poderia dar margem ao interlocutor pensar que os trabalhadores preferem responsabilizar a família a assumi-la como parte de um projeto terapêutico institucional. Isso seria um equívoco importante para um serviço que nasceu pela reinvenção das coisas e que preconiza a inclusão como premissa fundamental de sua prática.

Esse conjunto de manifestações atitudinais, que agregam juízo de valor aos eventos discursivos, servem para avaliar positiva ou negativamente o comportamento humano, sempre levando-se em consideração o conjunto de normas institucionalizadas pela sociedade. Essas normas que estão em jogo revelam regramentos, responsabilidades ou expectativas sociais, sendo, por isso, possível avaliar se o comportamento do sujeito está sendo moral, imoral, legal ou ilegal, socialmente aceitável ou não, normal ou anormal, e assim por diante (White, 2008).

Nesse sentido, em se tratando de processos enunciativos, o falante pode governar as condições contextuais e sintáticas necessárias para transmitir aquilo que obviamente quer transmitir. Tal justificativa se deve ao fato de que o enunciador se serve da linguagem para influenciar, em maior ou menor grau, o comportamento daquele que enuncia. Por exemplo, numa condição de interrogação, o enunciador pode querer suscitar uma "resposta"; quando afirma com muita certeza um fato, está na verdade promovendo uma "intimação" (uma ordem, um chamado). Essas relações revelam o potencial dialógico do discurso, as quais podem buscar, na materialidade da linguagem, sempre novas caracterizações para os mesmos eventos (Benveniste, 1999).

No caso da saúde mental, durante séculos sustentou-se a tese de que o fechamento da família sobre si mesma - às vezes associado à supervalorização, à idealização de uma família nuclear perfeita e à intensificação dos pensamentos de que a família não deve se dissociar ainda mais na situação de doença - contribuía para a constituição de um longo processo de culpabilização do grupo familial. Para mudar isso, é necessário repensar o lugar da família no tratamento, de preferência sem a formação de estereótipos que mais reforçam o isolamento do que o vínculo. A família precisa expandir, expressar sua singularização, problematizar a loucura para que possa ser re-significada enquanto parceira, e não como cúmplice ou vítima do processo de adoecimento psíquico (Melman, 2006).

No contexto do relacionamento interpessoal, é comum se agregarem juízos de valor aos comportamentos humanos. Representando a família como um grupo "desinteressado", por estar "afastado" do serviço, ou seja, culpabilizando esta por um evento relativamente discutível, o trabalhador vai transformando a "aliada" em "vilã" do tratamento. De um lado, fica o trabalhador que acolhe, mas responsabiliza; de outro, encontra-se a família, que se afasta porque quer, pode ou porque só necessita de um tempo para reorganizar-se e cuidar de suas outras demandas, muitas vezes esquecidas pelos encargos do sofrimento mental. Logo, com a falta de relacionamento dialógico, fica difícil envolver um grupo que já foi penalizado culturalmente por não saber "controlar o seu louco" perante a comunidade.

Uma das características mais marcantes da sociedade moderna está na construção de todo um 
sistema de culpabilização. Nesse sistema, os atores vão desenvolvendo mecanismos que servem de imagem de referência a fatos ou experiências vividas, que impõem certo grau de comparabilidade às ações humanas. A sociedade vai se condicionando ao enquadre de situações complexas da vida em grandes categorias unificadoras e redutoras, o que bloqueia o desenvolvimento da criatividade, da inovação e da transformação (Guattari, Rolnik, 2005).

Sendo assim, para re-significar o atendimento à família, não basta dizer que acolhemos para depois cobrarmos por esse acolhimento. Deve-se ter a consciência de que é preciso entendê-la como coletivo singularizado que se organiza como pode para participar do processo de reabilitação psicossocial. $O$ cuidado dos trabalhadores, livre dos juízos de valor negativo (afasta-se, nega, não aceita, desconhece), deve encarar a família como uma aliada no processo de tratamento do usuário. Independente de conhecer ou não, aceitar ou não, afastar-se ou não, inclusão implica valorização das subjetividades e protagonismo. Um protagonismo que é construído na convivência recíproca do cotidiano, quando serviço e família se entendem como parceiras, compartilham as dificuldades e propõem alternativas. Famílias e serviço, juntos, constroem relações genuínas, onde os juízos de valor moral que não agregam crescimento humano dão lugar à flexibilidade, à autonomia e à participação horizontal.

\section{Considerações finais}

Este estudo apresentou algumas das representações discursivas dos trabalhadores de saúde mental sobre a participação da família no tratamento do seu parente. Evidencia-se uma ênfase na culpabilização e na responsabilização do grupo familial, como se ele fosse responsável pelo seu afastamento do tratamento, quando, na verdade, não parece haver um movimento contrário que descubra os reais motivos para isso.

É claro que o fato de a família ser lembrada como copartícipe do tratamento é um avanço importante no contexto da reforma psiquiátrica brasileira. No entanto, é preciso repensar, no cotidiano da prática, sobre as estratégias de negociação com as famílias, para evitar que a parceria se transforme em responsabilização, assim como a contratualidade se transforme em culpabilização. Dimensões valorativas na prática que pouco auxiliam na ressignificação da loucura como fenômeno da existência, tampouco a sua inclusão no contexto da comunidade.

Esperamos que este estudo sirva de subsídio para promover a constante reflexão sobre o papel das famílias em saúde mental, temática importante para redimensionar saberes e práticas sobre o louco, a loucura e suas relações no contexto da reforma psiquiátrica.

\section{Colaboradores}

Os autores trabalharam juntos em todas as etapas de produção do manuscrito.

\section{Referências}

AREJANO, C.B. Reforma psiquiátrica: uma analítica das relações de poder nos serviços de atenção à saúde mental. 2002. Tese (Doutorado) - Programa de Pós-Graduação em Enfermagem, Universidade Federal de Santa Catarina, Florianópolis. 2002.

BENVENISTE, E. Problemas de lingüística general II. 15.ed. Madrid: Siglo Veintiuno, 1999.

BORBA, L.O.; SCHWARTZ, E; KANTORSKI, L.P. A sobrecarga da família que convive com a realidade do transtorno mental. Acta Paul. Enferm., v.21, n.4, p.588-94, 2008. 
BRASIL. Ministério da Saúde. Saúde mental no SUS: os Centros de Atenção Psicossocial. Brasília: Ministério da Saúde, 2004.

CHARAUDEAU, P.; MAINGUENEAU, D. Dicionário de análise do discurso. 2.ed. São Paulo: Contexto, 2006.

COSTA-ROSA, A. O modo psicossocial: um paradigma das práticas substitutivas ao modo asilar. In: AMARANTE, P. (Org.). Ensaios: subjetividade, saúde mental, sociedade. Rio de Janeiro: Fiocruz, 2000. p.141-68.

FAIRCLOUGH, N. Analysing discourse: textual analysis for social research. 4.ed. Great Britain: MPG Books, 2006.

GUATTARI, F.; ROLNIK, S. Micropolítica: cartografias do desejo. 7.ed. Petrópolis: Vozes, 2005.

KOGA, M.; FUREGATO, A.R. Convivência com a pessoa esquizofrênica: sobrecarga familiar. Cienc. Cuid. Saude, v.1, n.1, p.69-73, 2002.

LAKOFF, G. Metaphors we live by. Chicago: The University of Chicago Press, 1980.

LLISTERI, J. La representación ortográfica de corpus orales. Barcelona: Universidad Autónoma de Barcelona, 2008. Disponível em: <http://liceu.uab.cat/ joaquim/ language_resources/spoken_res/Repres_ortog_corp_oral.html>. Acesso em: 13 mar. 2009.

LOBOSQUE, A.M. CAPS: laços sociais. Mental, v.5, n.8, p.53-60, 2007.

LUZ, M. A história de uma marginalização: a política oficial de saúde mental. In: AMARANTE, P. (Org.). Psiquiatria social e reforma psiquiátrica. 3.ed. Rio de Janeiro: Fiocruz, 2008. p.85-95.

MELMAN, J. Família e doença mental: repensando a relação entre profissionais de saúde e familiares. 2.ed. São Paulo: Escrituras, 2006.

OLIVEIRA, A.G.B.; ALESSI, N.P. Superando o manicômio? Desafios para a construção da reforma psiquiátrica. Cuiabá: EdUFMT, 2005.

PINHO, L.B. Análise crítico-discursiva da prática de trabalhadores de saúde mental no contexto social da reforma psiquiátrica. 2009. Tese (Doutorado) - Escola de Enfermagem de Ribeirão Preto, Universidade de São Paulo, Ribeirão Preto. 2009.

PULIDO, R.; MONARI, M.; ROSSI, N. Institutional therapeutic alliance and its relationship with outcomes in a psychiatric day hospital program. Arch. Psychiatr. Nurs., v.22, n.5, p.277-87, 2008.

ROLLAND, J.S. Doença crônica e o ciclo de vida familiar. In: CARTER, B.; MCGOLDRICK, M. (Org.). As mudanças no ciclo de vida familiar: uma estrutura para a terapia familiar. 2.ed. Porto Alegre: Artmed, 2001. p.373-92.

ROMAGNOLI, R.C. Famílias na rede de saúde mental: um breve estudo esquizoanalítico. Psicol. Estud., v.11, n.2, p.305-14, 2006.

SARACENO, B. Libertando identidades: da reabilitação psicossocial à realidade possível. 2. ed. Rio de Janeiro: Te Corá, 2001.

WHITE, P.R.R. Un recorrido por la teoría de la valoración. 2008. Disponível em: <http://www.grammatics.com/appraisal/index.html>. Acesso em: 13 mar. 2008. 
PINHO, L.B.; HERNÁNDEZ, A.M.B.; KANTORSKI, L.P. Reforma psiquiátrica, trabajadores de salud mental y la cooperación de la familia: el discurso del distanciamiento. Interface Comunic., Saude, Educ., v.14, n.32, p.103-13, jan./mar. 2010.

Este estudio ha analizado el discurso de los trabajadores de salud mental sobre la participación de la familia en tratamiento. El corpus se compone de entrevistas aplicadas a 17 de los 25 profesionales que trabajan en un servicio substitutivo de una ciudad de la región Sur de Brasil. El referencial teórico-filosófico ha sido el Análisis Crítico del Discurso. El dispositivo metodológico que ha subsidiado la sistematización de los datos es el "diagrama axiológico-discursivo". Se verifica que los trabajadores manifiestan la importancia de la familia en el tratamiento del usuario; sin embrago representación aún pautada en la responsabilización y culpabilización, cuado la familia se aparta del tratamiento. Poco a poco la cooperación va dando espacio al distanciamiento como dimensión cuidadora en los servicios de salud mental. Se espera que este estudio pueda subsidiar la constante reflexión sobre el papel de las familias en salud mental, temática importante para repensar saberes y prácticas sobre lo loco, la locura y sus relaciones en el contexto de la reforma psiquiátrica.

Palabras clave: Estudios del lenguaje. Salud mental. Servicios de salud mental.

Recebido em 21/03/2009. Aprovado em 17/07/2009 